\title{
Breast Cancer Care: Patient Information and Communication as a Preventive Educational Process
}

\author{
Sabine Hawighorst-Knapstein \\ Dirk O. Brueckner \\ Götz Schoenefuss \\ Paul Georg Knapstein \\ Heinz Koelbl
}

Department of Obstetrics and Gynecology, University of Mainz, Germany

\begin{abstract}
Key Words
Breast Cancer - Anxiety - Information - Communication · Medical interaction - Quality of life
\end{abstract}

\section{Summary}

Background: The goals of medical interaction and communication are to provide information to promote biophysical and psychological health, prevent illness and cope with illness. According to the literature and the results of our own studies on quality of life, the first step medical staff should take in understanding the principles and processes of effective patient communication before and after treatment is to become familiar with the patient's needs and personal life. Patients and Methods: The systematic evaluation of quality of life and anxiety has been part of the clinical routine in our own prospective studies for all women with breast cancer since 1999. Results: Anxious patients require more knowledge about their illness and increased control of chronic illness not only before surgery but also in the long run in the advanced stages of disease and after extensive surgery. Thus, before surgery, information may decrease anxiety and increase patient satisfaction. After surgery, the patient's self-esteem may be enhanced by information and support, not only on medical issues but also on selfcare skills which may result in an improved physical and psychosocial status. Conclusions: The above findings may create more knowledge about the process of medical interaction related to the therapeutic outcome and individual risk factors, especially in times of early discharge, as well as the use of outpatient facilities for many procedures. Women with breast cancer should be counselled about the role of anxiety and problems of understanding medical issues prior to each medical decision. Physicians may help patients to organise their psychosocial problems before each therapeutic step in order to overcome feelings of anxiety, lack of control and self-esteem by a holistic understanding of the 'informed consent' process before, during and after treatment for breast cancer as a preventive team approach.

\section{Schlüsselwörter}

Brustkrebs · Angst · Information .

Medizinische Interaktion · Lebensqualität

\section{Zusammenfassung}

Hintergrund: Das Ziel medizinischer Interaktion und Kommunikation besteht darin, Informationen zu übermitteln, um biophysische und psychologische Gesundheit zu unterstützen, Krankheit vorzubeugen und diese bestmöglich zu bewältigen. Der erste wichtigste Schritt vonseiten des medizinischen Personals für eine effiziente Kommunikation mit den Patientinnen ist, sich vor und nach medizinischen Behandlungen mit den Bedürfnissen, Wünschen und auch der Lebenssituation der Betroffenen auseinanderzusetzen, wie unsere eigenen Untersuchungen aber auch Literaturerkenntnisse ergeben. Patienten und Methoden: Die systematische Evaluation von Lebensqualität und Angst wird seit 1999 routinemäßig bei allen unseren prospektiven Studien mit Brustkrebspatientinnen durchgeführt. Ergebnisse: Insbesondere ängstliche Patientinnen wünschen sich mehr Informationen zu und Kontrolle über ihre Erkrankung und Behandlung, sowohl prä- als auch längerfristig postoperativ, vor allem bei ausgedehnten Operationen. Präoperativ kann Information daher Angst mindern und die Arzt-Patient-Beziehung günstig beeinflussen. Postoperativ kann das Selbstwertgefühl und die Eigenkompetenz der Patientinnen durch gezielte Informationen gestärkt werden, was somit einen günstigen ganzheitlichen Effekt hat. Schlussfolgerungen: Die beschriebenen Darstellungen und auch die Erkenntnisse der eigenen Untersuchungen beleuchten den Prozess der medizinischen Interaktion und seine Bedeutung für die medizinische Behandlung auch bezogen auf individuelle Risikofaktoren, vor allem in Zeiten rascher Entlassung und wachsender ambulanter Versorgungsmöglichkeiten. Frauen mit Brustkrebs sollten hinsichtlich ihrer Ängste und Sorgen vor jeder medizinischen Entscheidung beraten und unterstützt werden. Ärzte können hier helfen, Lösungen vor einer Behandlung zu finden, um Gefühle von Kontrollverlust und Unzufriedenheit mit der medizinischen Kommunikation frühzeitig aufzufangen, und sie als gemeinsame Interaktion auch längerfristig über alle Behandlungsphasen präventiv im Team zu gestalten.

\begin{tabular}{ll}
\hline KARGER & @ 2006 S. Karger GmbH, Freiburg \\
Fax +49 7614520714 & Accessible online at: \\
$\begin{array}{l}\text { E-mail Information@Karger.de } \\
\text { www.karger.com }\end{array}$ & www.karger.com/brc
\end{tabular}

\section{KARGER}

www.karger.com
Dr. habil. Sabine Hawighorst-Knapstein

Klinik und Poliklinik für Geburtshilfe und Frauenheilkunde

Johannes-Gutenberg-Universität Mainz

Langenbeckstraße 1, 55101 Mainz, Germany

Tel. +49 6131-364133, Fax -331337

E-mail Dr.Sabine.Hawighorst-Knapstein@gyncom.de 


\section{Introduction}

The shock of the diagnosis 'breast cancer' changes a woman's daily life profoundly and she suddenly finds herself in a situation where she has to make radical decisions about her body with unknown consequences for her physical and psychological long-term adaptation.

The question in this context is what kind of psychosocial factors are relevant for women with breast cancer related to the therapeutic procedure and may have long-term effects on their physical and psychosocial well-being. These findings may create more knowledge about the process of medical interaction related to the therapeutic outcome and individual risk factors, such as the preoperative anxiety level, and preventive counselling skills. For example, women with breast cancer may be counselled about the role of anxiety and problems of understanding medical issues before each medical decision is made [1]. Physicians may help their patients to organise their psychosocial problems before each therapeutic step in order to overcome feelings of anxiety and helplessness by providing information, knowledge and support as a holistic understanding of the 'informed consent' process.

About $80 \%$ of all breast cancer tumours will be detected by the women themselves, and many efforts are made to increase the rate of early diagnosis of breast cancer (programs for regular self-examination of the breast, screening etc.). However, many women feel anxious about their findings and often tend to wait too long, especially if they are older and may feel ashamed about this topic, whereas younger women may overestimate their breast cancer risk due to anxiety.

A person who acquires knowledge, skills, or behaviour change as a result of instruction or study may be encouraged to play a more active role in order to combine biophysical (age, pain, visual symptoms of their breast) and psychological (anxiety, defensiveness, signs of stress response to personal problems, sexuality, coping mechanisms) dimensions. Assessments of these areas becomes important when developing an information and education plan for a woman who will be receiving acute or palliative therapy. Nowadays, efforts to address physical and psychosocial sequelae of stage of disease and treatment procedure are present in rehabilitation programs but not yet systematically before the process of decision making is started.

Patient education in this context means a planned learning experience using a combination of methods, such as information, counselling and behaviour modification techniques (e.g. relaxation) that influence the patient's knowledge as a preventive educational approach for a better quality of life. Learner readiness may increase when even the smallest need is met. Thus, the educational process between patient and physician (or nurse) depends on a complete and accurate assessment of the patient's physical and psychosocial status before and after treatment for breast cancer.

\section{Patient Assessment for Anxiety}

Serious disturbance in the sense of psychiatric diagnosis using the DSM (Diagnostic and Statistical Manual of Mental Disorders)-III criteria may be limited to about $10 \%$ of breast cancer patients and may vary related to stage of disease and extent of treatment [2]. Anxiety for example is associated with more severe post-treatment symptoms and exacerbates pain. According to many studies, anxiety disorders are prevalent for many cancer patients. Studies using the HADS (Hospital Anxiety and Depression) scale reported a high correlations between the subscales for anxiety and depression for cancer patients as well as the STAI (State-Trait Anxiety Inventory) and BDI (Beck Depression Inventory) [3, 4]. Acutely anxious patients may be unable to understand or tolerate treatment procedures. Some studies found greater anxiety in younger patients, and anxiety seems to increase with the stage of disease $[4,5]$. Especially the extent of breast cancer treatment can potentially reduce quality of life and body image in the long run $[6,7]$. In our own studies, which started in 1993, on various genital cancers, we assessed the interferences between biophysical and psychological dimensions to learn more about preventive information and communication tools.

\section{Patients and Methods}

\section{Patients}

In this paper, we focus on some psychological dimensions in women with breast cancer, such as anxiety and quality of life, and compare the results with the literature $[8,9]$. The systematic evaluation of quality of life and anxiety has been part of the clinical routine in our own prospective studies for all women with breast cancer since 1999. A team of psychologically and psychotherapeutically trained physicians and psychologists assessed all women before surgery (T1) and interviewed 412 women between 3 and 6 times in a semistructured 30-min interview at predefined stages (T2-T6). The first interview was held a few days before surgery. The last interview was performed 1 year after surgery. Eligibility criteria included being scheduled for cancer treatment, ability to read and speak German fluently and the absence of psychiatric disease.

\section{Assessment of Quality of Life and Anxiety}

For assessment of quality of life, a battery of assessments was introduced beginning with a cancer-specific rehabilitation- and treatment-planning questionnaire, the Cancer Rehabilitation Evaluation System (CARES) [10]. The global CARES score is a summary score that reflects the patient's overall quality of life: physical health, psychosocial function, sexual function, medical interactions and marital interactions. The psychosocial

Table 1. Questionnaires for the assessment of quality of life

\begin{tabular}{lll}
\hline Questionnaires & Authors & Items \\
\hline CARES & Schag et al. 1988 [19] & 59 \\
EORTC & Aaronson et al. 1993 [11] & 30 \\
FBK & Herschbach et al. 1986 [20] & 38 \\
STAI & Spielberger et al. 1981 [21] & 20 \\
FKE & Strauß and Appelt 1996 [22] & 52 \\
\hline
\end{tabular}




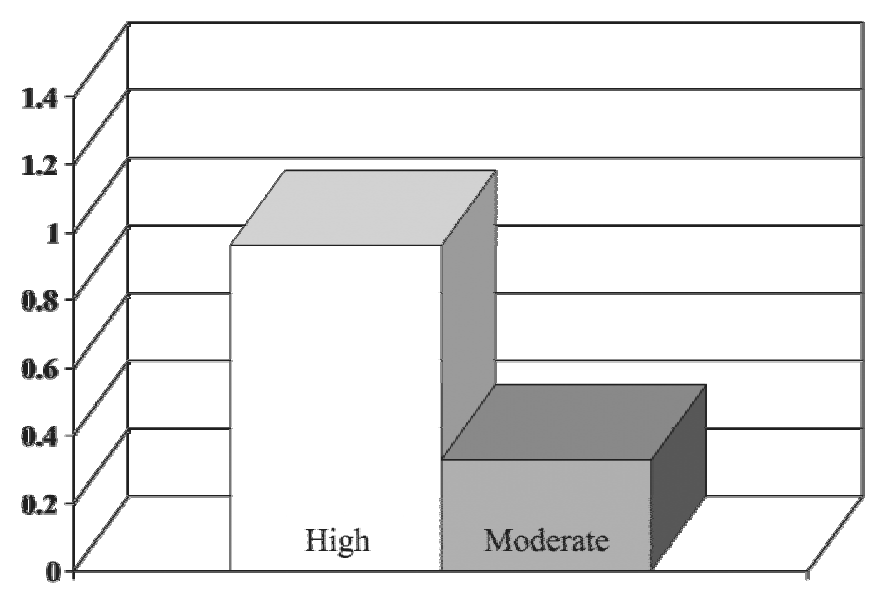

Anxiety

Fig. 1. Level of anxiety: 'I find that doctors don't explain what they are doing to me'.

domain includes psychological issues and problems related to communication and relationships other than with a partner. Medical interactions refer to problems concerning interaction and communication with the medical staff ('I would like to know more about my disease' and 'I would like to have more control on what physicians are doing to me' etc.).

Quality of life was also evaluated with the European Organisation for Research and Treatment of Cancer (EORTC) questionnaire [11] and 2 other German questionnaires for coping (Fragebogen zur Belastung von Krebskranken, FBK) and body image (Fragebogen zum Körpererleben, FKE), which are not in the focus of this article (table 1). The preoperative anxiety level was evaluated by STAI [12].

\section{Results}

In this article, we focus on the most relevant findings concerning psychosocial problems before surgery. 312 women with various types of either breast or genital cancer were assessed prior to surgery. In all women, the anxiety level before surgery was significant and was not related to the patient's age or other sociodemographic factors. There was a strong correlation, however, between the state of anxiety and the quality of life summary score for women with either type of cancer: the dimension of medical interaction correlated with the preoperative anxiety level measured by STAI and CARES ( $p=0.000, r=0.671)$. To clarify the importance of the relation between preoperative anxiety and quality of life, patients were allocated into groups with 'high anxiety' or 'moderate anxiety'. The more anxious patients stated a significant lack of medical explanation, showed significantly more difficulty in understanding medical information, and felt significantly more helpless in the medical setting than women with moderate anxiety reflected by STAI (fig. 1) [13, 14]. Thus, women with a high anxiety level (every second woman of all cancer patients) indicated for example that they wished to have more information about their disease and to gain more control over the therapeutic process. This result represents an essential finding in all women assessed before cancer surgery.

\section{Discussion}

The focus of health care has radically changed over the last decade towards prevention of complication and, if possible, illness. Patients are being encouraged to play an active role in the decision-making process. According to our own studies and the literature, effective patient education may result in increased knowledge about treatment and complications, increased patient satisfaction, decreased anxiety and better quality of life.

The interesting focus in our own studies underlines the interferences between anxiety and medical interaction before surgery. At this time, the patient's education process should be planned carefully related to the patient's emotional status and psychosocial problems and not only to the individual medical situation, maybe based on a psychometric screening in daily clinical routine or just by talking about these aspects directly ('Take your time to feel well informed about your treatment options'). Communication skills are very important before surgery and may result in improved control over disease from the patients' point of view, in order to enhance patient recovery, to reduce readmissions to the hospital or home care, to prevent complications after treatment and to improve quality of life.

Most studies focus on aspects of psychosocial adaptation of cancer survivors in the long run, when and how to 'function' again, and if post-traumatic stress disorders appear [15]. However, the psychosocial adjustment process starts with the shock of diagnosis, and the prevention of unmet needs may be an important topic right from the beginning of therapy or even before [5, 7]. Few studies focus on anxiety before surgery but some researchers have used well-established instruments, such as the mentioned HADS, STAI etc. [2, 4], where approximately every third woman with breast cancer indicated psychiatric symptoms.

The aim of early psychosocial attentiveness is not to overestimate the patient's 'normal' adaptation process but to anticipate further problems regarding quality of life and anxiety related to the diagnosis and treatment process and to balance them with the individual fears, problems and values. The time before any treatment choices are made is most important to the patient's well-being in the long run. Rehabilitation is a very important helpful process especially for patients with advanced and/or mutilating cancer treatment, but feelings such as anxiety, helplessness, loss of control and isolation should be addressed right from the beginning of any therapeutic decision making.

The majority of women with breast cancer will be cured, and an important question is how quality of life will be altered in the long run due to the surgical procedure [16, 17]. Many women will be very anxious before surgery and due to the shock of the diagnosis, but there is no need to rush into surgery without paying regard to the individual perspectives from a holistic point of view. Thus, the doctors' communication skills should integrate not only the knowledge about the 
treatment procedures but also the patient's point of view in her individual life situation right from the beginning [18].

For example, women diagnosed with early breast cancer due to careful and regular breast self-examination may not only be cured but may have a very good quality of life due to breast conserving therapy. Women with aggressive types of cancer or mastectomy due to advanced stages of disease may suffer from psychosocial sequelae due to mutilating surgery and aggressive chemotherapy, especially if they are young mothers or single or without social support or have other social stress factors at work or at home. Subsequently, the psychosocial care process may be different for each patient related to diagnosis and treatment according to her personal fears and medical situation.

The impact of being diagnosed with cancer starts right with the diagnosis and cannot be separated into physical and psychological consequences as the medical treatment process generally implies. Patient education not only on medical but also on health and psychosocial aspects is a collaborative and integrative effort of the health care team, the patient, family members and friends who may provide as good a care as social workers and psychologist. This process begins with the phase of diagnosis and continues throughout the treatment and follow-up phase by seeking feedback on the patient's understanding at each level from treatment to lifestyle aspects as well as on the process of psychosocial adaptation.

The supportive role of the medical staff should not be underestimated during cancer treatment and the follow-up phase. Balanced communication skills with regard to physical and psychosocial sensitivity during all phases of diagnosis and treatment, primary or relapse, can meet the patient's needs and improve quality of life effectively before and after treatment, as our own studies and the literature indicate.

\section{Recommendation for Psychosocial Prevention in 5 Steps}

1. Try to evaluate the patient's anxiety level right from the beginning according to your communication skills by interview and/or psychometric assessments.

2. After step 1, try to address the patient's fears right from the beginning, also together with her family members.

3. Try to address the long-term effects of surgery on the patient's physical and psychological status before surgery related to the stage of disease.

4. Try to offer women with personal problems support as early as possible before treatment, either in psychological and/or social ways (husband or small children needing care etc.).

5. Try to organise support right after the shock of diagnosis in order to decrease anxiety and to increase patient satisfaction with the care process and to improve daily functioning.

\section{Acknowledgement}

This study was supported by the H.W. and J. Hector Foundation.

\section{References}

1 Neises M, Ditz S, Spranz-Fogasy T: Psychosomatische Geprächsführung in der Frauenheilkunde. Ein interdisziplinärer Ansatz zur verbalen Intervention. Stuttgart, Wissenschaftliche Verlagsgesellschaft, 2005.

2 Moorey S, Greer S, Watson M, Gorman C, Rowden L, Tunmore R, Robertson B, Bliss J: The factor structure and factor stability of the hospital anxiety and depression scale in patients with cancer: $\mathrm{Br} \mathrm{J}$ Psychiatry 1991;158:255-259.

3 Zigmond AS, Snaith RP: The hospital anxiety and depression scale. Acta Psychiatr Scand 1983;67: 361-370.

4 Carroll BT, Kathol RG, Noyes R, Wald TG, Clamon GH: Screening for depression and anxiety in cancer patients using the hospital anxiety and depression scale. Gen Hosp Psychiatry 1993;15: 69-74.

5 Lee MS, Love SB, Mitchell JB, Parker EM, Rubens RD, Watson JP, Fentiman IS, Hayward JL: Mastectomy or conservation for early breast cancer: Psychological morbidity. Eur J Cancer 1992;28A:1340 1344.

6 McArdle JM, Hughson AV, McArdle CS: Reduced psychological morbidity after breast conservation. Br J Surg 1990;77:1221-1223.

7 Fallowfield LJ, Hall A, Maguire GP, Baum M: Psychological outcomes of different treatment policies in women with early breast cancer outside a clinical trial. BMJ 1990;301:575-580.
8 Abeloff M, Armitage J, Niederhuber J, Kastan M, McKenna WG: Clinical Oncology. Philadelphia, Churchill Livingstone, 2004.

9 Holland JC, Breitbart W, Jacobsen PB, Lederberg MS, Loscalzo M, Massie MJ, McCorkle R: Psychooncology. New York, Oxford University Press, 1998.

10 Schag CA, Ganz PA, Heinrich RL: Cancer rehabilitation evaluation system - short form (cares-sf). A cancer specific rehabilitation and quality of life instrument. Cancer 1991;68:1406-1413.

11 Aaronson NK, Ahmedzai S, Bergman B, Bullinger M, Cull A, Duez NJ, Filiberti A, Flechtner H, Fleishman SB, de Haes JC: The European organization for research and treatment of cancer qlqc30: a quality-of-life instrument for use in international clinical trials in oncology. J Natl Cancer Inst 1993;85:365-376.

12 Laux L, Glanzmann P, Schaffner P, Spielberger CD: Das State-Trait-Angstinventar. Palo Alto, Consulting Psychologists Press, 1980.

13 Hawighorst S, Schoenefuss G, Fusshoeller C, Franz C, Seufert R, Kelleher DK, Vaupel P, Knapstein PG, Koelbl H: The physician-patient relationship before cancer treatment: a prospective longitudinal study. Gynecol Oncol 2004;94:93-97.

14 Hawighorst-Knapstein S, Fusshoeller C, Franz C, Trautmann K, Schmidt M, Pilch H, Schoenefuss G, Knapstein PG, Koelbl H, Kelleher DK, Vaupel P: The impact of treatment for genital cancer on quality of life and body image - results of a prospective longitudinal 10-year study. Gynecol Oncol 2004; $94: 398-403$.
15 Herschbach P, Henrich G: Problems and coping with problems by tumor patients in inpatient after care. Psychother Psychosom Med Psychol 1987;37: 185-192.

16 Schover LR, Yetman RJ, Tuason LJ, Meisler E, Esselstyn CB, Hermann RE, Grundfest-Broniatowski S, Dowden RV: Partial mastectomy and breast reconstruction. A comparison of their effects on psychosocial adjustment, body image, and sexuality. Cancer 1995;75:54-64.

17 Sneeuw KC, Aaronson NK, Yarnold JR, Broderick M, Regan J, Ross G, Goddard A: Cosmetic and functional outcomes of breast conserving treatment for early stage breast cancer. 1 . Comparison of patients' ratings, observers' ratings, and objective assessments. Radiother Oncol 1992;25:153159.

18 Haug M: The effects on physician/elder patient characteristics. Health Commun 1996;8:249-262.

19 Schag CAC, Heinrich RL: Cancer Rehabilitation Evaluation System (CARES) Manual. Los Angeles, CA, CARES Consultants, 1989, pp 1-83.

20 Herschbach P, Rosbund AM, Brengelmann JC: Probleme von Krebspatientinnen und Formen ihrer Bewältigung. Onkologie 1985;8:219-231.

21 Spielberger CD, Laux L, Glanzmann P, Schaffner P: Das State-Trait-Angstinventar. Consulting Psychologists Press, Palo Alto, 1981.

22 Strauss B, Appelt H: Ein Fragebogen zur Beurteilung des eigenen Körpers. Diagnostica 1983;29: 145-164. 